\title{
That's the way the cookie bounces: Syntactic and semantic components of experimentally elicited idiom blends
}

\author{
J. COOPER CUTTING and KATHRYN BOCK \\ University of Illinois at Urbana-Champaign, Champaign, Illinois
}

\begin{abstract}
Idioms are sometimes viewed as unitized phrases with interpretations that are independent of the literal meanings of their individual words. In three experiments, the nature of idiom representation was explored with a speech-error elicitation task. In the task, speakers briefly viewed paired idioms. After a short delay they were probed to produce one of the two idioms, and their production latencies and blend errors were assessed. The first experiment showed greater interference between idioms with the same syntactic structure, demonstrating that idiom representations contain syntactic information. The second experiment indicated that the literal meaning of an idiom is active during production. These syntactic and literal-semantic effects on idiom errors argue against a representation of idioms as noncomponential lexicalized phrases. In the final experiment, no differences were found between decomposable and nondecomposable idioms, suggesting that the lexical representation of these two types of idioms is the same.
\end{abstract}

Recently, a friend commented that "the road to Chicago is straight as a pancake." This was a blend of two idioms, straight as an arrow and flat as a pancake. Although slips of the tongue are often studied in order to provide insight into language-production processes, phrase and idiom blends have received little attention (Fay, 1982; Garrett, 1980). The purpose of the experiments presented here was to examine such errors for clues to the nature of idiom representation.

Idioms are often regarded as phrases with interpretations that are not directly related to the literal meanings of their individual words (Dik, 1989; Fraser, 1970; Katz \& Postal, 1963; Weinreich, 1969; Wood, 1986). Challenges to this view have come from psycholinguistic research on how idioms are understood. This research has focused mainly on two related issues: (1) how idioms are mentally represented, and (2) whether their literal meaning plays any role in their use.

The standard pragmatic model of idiom comprehension (Bobrow \& Bell, 1973; Katz \& Postal, 1963) proposes that idioms are stored as whole chunks, roughly

\footnotetext{
The experiments reported here are part of the first author's master's thesis presented to the Department of Psychology at the University of Illinois at Urbana-Champaign. The research was supported in part by grants from the National Science Foundation (BNS 90-0961 1, SBR 9411627 ) and the National Institutes of Health (R01 HD21011). Portions of the work were presented at the 66th Annual Meeting of the Midwestern Psychological Association in Chicago, in 1994. The authors thank Gary Dell, Gregory Murphy, Rose Zacks, and Thomas Carr, for their comments and suggestions, and Brian Kleiner, for his assistance in administering the experimental tests and in scoring transcriptions. Requests for reprints and other correspondence may be sent to J. C. Cutting, Department of Psychology, University of Illinois, 603 E. Daniel St., Champaign, IL 61820 (e-mail: jcutting@s.psych.uiuc.edu).
}

equivalent to a single word, in an idiom lexicon that is separate from the general lexicon. The model further proposes that the literal meaning of a phrase is first derived and then checked against its context. If this meaning fails to fit the context, then the idiom lexicon is consulted for retrieval of the figurative meaning of the idiom. This model rests on the assumption that literal meaning is always determined and that this determination precedes figurative interpretation.

Challenging the literal-first proposal, Swinney and Cutler (1979; see also Gibbs, 1980, 1986) showed that idioms were classified as acceptable English phrases faster than matched control strings. They proposed that an idiom was represented as a single lexical unit within the general lexicon, rather than in a special lexicon (see also Fraser, 1970 ; Katz, 1973). Retrieval and storage of an idiom proceeds in the same way as any other word, with access to literal and figurative meanings occurring simultaneously.

A strong interpretation of Swinney and Cutler's (1979) unitization hypothesis suggests that the idiomatic phrase is just a large word-like unit. The internal components have no identity as individual lexical items, blurring or losing information about grammatical class, syntactic structure, and semantics. This interpretation is questionable because idiom representations must retain some information about the internal components (Katz, 1973): They need phonological information in order to appropriately assign stress and syntactic information about the components, because many idioms are syntactically flexible. For example, lay down the law can be syntactically manipulated without losing its idiomatic meaning, as in "after the law had been laid down by John, there was no more trouble."

A weaker interpretation of the unitization hypothesis retains structural information in the representation. Fraser 
(1970) proposed that a phrasal idiom was a single lexical item that contained multiple complex symbols (syntactic features and phonemic representations) but a single semantic marker. For example, the idiom "hit the sack" might be abstractly represented as $([+\mathrm{V}]$ hit; $[+\mathrm{DET}]$ the; [+N] sack; \{go to bed $\}$ ), but without semantic information associated to the individual parts of the idioms. Instead, there is a single semantic interpretation for the idiom as a whole. This solves the problem of syntactic flexibility, but raises another. Idioms vary in the extent to which they can undergo lexical manipulation without disrupting their figurative meaning (Gibbs, Nayak, Bolton, \& Keppel, 1989). Wasow, Sag, and Nunberg (1983) showed that the individual parts of some idioms can be internally modified by the insertion of adjectives or quantifiers as in "Mary really touched a couple of nerves." Likewise, one can emphasize the parts of idioms through topicalization, as in "The strings that John was able to pull seemed to be the right ones for getting the job." Thus, aspects of an idiom's overall meaning can be altered by modifying its individual components, implying that the meanings of these individual parts contribute meaning to the whole.

To explain these properties of idioms, Nunberg (1978) proposed the idiom decomposition hypothesis. This hypothesis suggests that idioms are not single lexical units, either lexically or semantically, but partially analyzable phrases. Their productive behavior is determined by the assumptions that a speaker makes about how the meanings of the parts contribute to the figurative meaning of the whole (see also Cacciari \& Glucksberg, 1991; Gibbs \& Nayak, 1989; van der Linden, 1989; Wasow et al., 1983; Wood, 1986). The theory argues that idioms exist on a continuum of decomposability. The idiom pop the question is considered decomposable because its component parts refer, in some way, to their idiomatic referents. Pop refers to "a sudden noise" (that of speaking) and the question refers to "a proposal of marriage." Such idioms are predicted to be syntactically flexible. In contrast, for the nondecomposable idiom kick the bucket, it is hard to imagine what the relationship between the components and their idiomatic meaning is. This idiom should be syntactically inflexible ("frozen"; see Fraser, 1970). Supporting this hypothesis, Gibbs and Nayak (1989) found the decomposability of idioms to be highly correlated with their syntactic flexibility.

Although most psycholinguistic research on idioms has addressed how they are understood (Cacciari \& Glucksberg, 1991; Gibbs \& Nayak, 1989), the issues of representation and literal meaning use also arise with respect to the production of idioms. A production hypothesis derived from either the standard pragmatic model or the unitization hypotheses might suggest that idioms are represented and accessed as whole units. Furthermore, a strict division between an idiom's figurative meaning and the literal meaning of its individual parts would predict that, in speaking, one should be able to access an idiom without interference from the literal meanings of its component words. This is because speakers have in mind the idea that is to be conveyed prior to producing an idiom, and that idea presumably maps onto the figurative meaning. For example, a speaker who intends to convey the idea that somebody died suddenly can say "he kicked the bucket" without accessing the literal interpretation "he knocked the pail over with his foot."

The standard pragmatic hypothesis for production suffers from the same problem that its comprehension predecessors did. If idioms were single units, lexical and syntactic variations could not be produced. As an alternative, Cacciari and Glucksberg (1991) proposed that idioms were retrieved as phrases in which the internal components retained individual syntactic and semantic annotations. They further argued that both the literal and figurative meanings played a role in using idioms generatively in discourse. The literal meaning of an idiom's components mediates the production of idiomatic variants, both lexical and syntactic (McGlone, Glucksberg, \& Cacciari, 1994). For example, "once the ice was shattered, the party became much more enjoyable," retains the basic idiomatic meaning of break the ice, but with a nuance from the literal meaning of shattered.

The present experiments were designed to explore these issues in idiom representation by examining speech errors that accidentally combine two different idioms, or idiom blends. Blends in general are viewed as the result of two competing speech plans which interfere with one another ${ }^{1}$ (Baars, 1980a; Fay, 1982; Fromkin, 1971; Harley, 1984; Levelt, 1989; Motley, Baars, \& Camden, 1983a, 1983b). The term blend thus refers to the replacement of an element related to one speech plan by an element related to another speech plan, resulting in an utterance that does not exactly match either one.

The most familiar blends involve individual words: (1) The competition is a little stougher [stiffer/tougher] (Fromkin, 1973), (2) Irvine is quite clear [close/near] (Fromkin, 1973), and (3) ... and would like to enlicit [enlist/elicit] your support (Garrett, 1980). Examples 1 and 2 illustrate the strong semantic relationships typical of word blends (Fromkin, 1971; Garrett, 1980; ShattuckHufnagel, 1979) and Example 3 illustrates a phonological relationship (Dell \& Reich, 1981). The errors usually combine words from the same syntactic class (Butterworth, 1982; Harley, 1984; Levelt, 1989) and respect syllable boundaries (MacKay, 1972).

If idioms are single lexical items, as the strong version of the unitization hypothesis suggests, then one would expect them to demonstrate only characteristics similar to those just described for word blends. Idioms of similar figurative meaning should be most likely to blend together, but these errors should be independent of the internal syntax of the idiom. On the other hand, the weak unitization and decomposability hypotheses suggest that the representation of an idiom includes syntactic information. In this case, one would expect that syntactic information should influence the production of errors such that idioms with the same syntactic structure should interfere with one another more than those with different structures, resulting in more idiom blends. Furthermore, 
substituted words should tend to be of the same grammatical class as the idiomatic components that they replace.

If idioms are partially analyzable phrases, then blends between them should resemble phrase blends more than word blends. Although relatively little is known about phrase blends, their occurrence is well attested. Butterworth (1982) attributed them to interference between two alternative but complete formulations of an intended thought. The result may be a syntactic blend (e.g., "I could never did find it" is a blend of "I could never find it" and "I never did find it"; Stemberger, 1982) or a blend of alternative plans with related meanings but widely different surface structures (e.g., "I miss being out of touch with academia" is a blend of "I miss being in touch with academia" and "I am out of touch with academia").

Phrase blends are a diverse lot. A small corpus compiled by Fay (1982) is made up of $15 \%$ substitution blends (combining words from competing phrases; e.g., "It's spent me a year ..." from "It's taken me a year" and "I spent a year"), $21 \%$ splice blends (tacking part of one phrase onto a competitor; e.g., "She looks it that type" from "She looks it" and "She looks that type"), and 59\% blends that exhibited both of these characteristics ("I've never had such worse hands" from "I've never had such bad hands" and "I've never had worse hands"). The remaining 5\% were complex errors.

There is anecdotal evidence that idioms, like phrases, blend. In Stemberger's (1985) corpus of speech errors, idioms appear in blends in which an entire word from one idiom replaced a word in another (69 instances) or component words themselves blended ( 9 instances). Notably, the word replacements sometimes involved words that were similar in literal meaning. Stemberger observed that the predominance of word replacements suggests that the blends occurred mostly at a level where words were represented as wholes rather than individual speech sounds.

Because idiom blends occur too rarely in spontaneous speech to reveal much about how idioms are represented and processed in production, the present research employed a controlled error-elicitation procedure. Our method, like other methods for inducing unintentional speech errors, involved presenting speakers with two alternative production targets. The speakers are required to produce only one while under time pressure (Baars, 1980a, 1980b). These techniques have been applied most extensively to elicit sound exchanges, but Motley (1985) sketched a related technique for eliciting phrase errors. Two sentences were presented to speakers for $10 \mathrm{sec}$, tagged by a single letter: T: Do I have to put on my seat belt? and M: Do I have to put my seat belt on? After a 5-sec delay, one of the letters ( $\mathrm{T}$ or $\mathrm{M}$ ) was presented as a cue to produce the corresponding sentence. The task reportedly elicited blends like "Do I have to put on my seat belt on?" (also see Lapointe \& Dell, 1989).

In the three experiments below, speakers were briefly shown two idioms. After a short pause, they were cued to produce one or the other as quickly as they were able. In the first experiment, the syntactic and semantic properties of the competing idioms were manipulated to see whether idioms with the same syntactic frame were more or less likely to interfere with one another, and whether idioms with the same figurative meaning were more or less likely to interfere with one another. The second experiment used pairs of phrases, one an idiom and the other a phrase with a meaning similar to or different from the idiom's literal meaning. If literal meaning plays a role in idiom production, literally similar phrases should blend with idioms more often than literally dissimilar phrases. The final experiment examined whether paired decomposable idioms were any more likely than paired nondecomposable idioms to interfere with one another. If decomposability is important for the production of idioms, decomposable idioms should be easier to modify and thus more susceptible to production errors.

The goal of the three experiments was to explore some of the representational factors that constrain idiom errors, particularly their meanings (both literal and figurative) and their syntax. The focus was on idiom blends, with the assumption that constraints on idiom errors might reflect fundamental features of the idiom representation. In general, if idioms are lexicalized phrases without internal syntactic and semantic structure, the structure and literal meaning of competing idioms should not affect production. However, if an idiom's representation is articulated in terms of both structure and meaning, idiom blends should respect the structures and meanings of the competitors.

\section{EXPERIMENT 1}

In this experiment, speakers were induced to create idiom errors with a competing-plans methodology. The speakers silently read two idioms from a computer screen, and shortly thereafter they were cued to produce one or the other idiom. Paired idioms had the same or different idiomatic meaning and the same or different syntactic form. The question was whether these two factors constrain idiomatic speech errors. The decomposability hypothesis and both unitization hypotheses predict that idiom pairs with similar figurative meanings should produce more interference than those with different meanings, resulting in longer naming latencies and more blends. The hypotheses differ in their predictions about the effect of syntactic structure. If idioms are completely lexicalized phrases, as the strong unitization view would have it, the syntax of an idiom should not play a significant role in the production of blends. On the other hand, if idiomatic representations encode information about internal syntax (as decomposability and weak unitization suggest), then idiom pairs with identical syntactic forms should produce more interference (more blends and longer production latencies) than those with different syntactic forms.

\footnotetext{
Method

Participants. Ninety-six Michigan State University students participated in the main experiment for extra credit in introductory psy-
} 
chology classes or for payment. Five were replaced because they reported that they were unable to read both of the idioms in the time allowed. An additional 80 students served in idiom norming studies. None of them took part in the main experiment. All of the students were native speakers of English.

Materials. The idioms were assembled from a list of 129 American idioms from Makkai (1987) and 129 additional literal phrases. These materials were normed prior to the experiment in order to assess their idiomatic properties. In the first norming study, 40 students were asked to rate the phrases on a 5-point idiomaticity scale $(1=$ not an idiom, $5=$ very idiomatic $)$. The idioms selected for the experiment had a median score of 4.2 and a range from 2.9 to 5.0. In comparison, the literal phrases yielded a median score of 2.0 and a range from 1.1 to 4.0 (only six had mean ratings higher than 3.0).

In the second norming study, another 40 participants received a list of paired idioms and were asked to rate on a 5-point scale whether the two phrases had the same meaning (5) or different meanings (1). The median meaning-similarity ratings for the items used in the experiment are presented in Table 1.

Thirty-six experimental items were formed, each with three versions. Each version contained a pair of idioms. One idiom, the standard, appeared in all pairs. In one experimental condition, the standard idiom and its pairmate had similar figurative meanings and the same syntactic structures (e.g., if the standard idiom had the structure verb-determiner-noun, so did the paired idiom). In a second condition, the standard idiom and its pairmate had the same syntactic form but different figurative meanings. In the final condition, the standard idiom and its pairmate had different syntactic forms (e.g., if the standard idiom was verb-determiner-noun, then the paired idiom might have the structure preposition-determiner-noun) and different figurative meanings. We will call these respective conditions same meaning-same syntax, different meaning-same syntax, and different meaning-different syntax. Table 1 gives an example of an item in each of the three conditions and the median idiomaticity rating for each type of idiom. In addition to the experimental idioms, 72 other idiom pairs were used as practice and filler items. All of these pairs differed in syntactic form and figurative meaning. All of the idioms in a pair had the same number of words. The median number of words in the idioms across all of the experimental items was three. The Appendix lists the complete idiom set.

Procedure. Speakers were tested individually, and each session was recorded on audio tape. The stimuli were presented visually on the screen of a Macintosh computer with an EMM-2048a Universal Microcontroller (Metaresearch Inc.) for millisecond timing. Responses were spoken into a microphone that was attached to a voice key (Gerbrands Corporation, Model G1341T), which in turn signaled the computer that a response had been made.

Figure 1 depicts an example of a typical trial. The idioms in each pair were presented one above the other, left justified, in the center of a computer screen. A single experimental trial proceeded as follows. The speaker viewed a pair for a period of time that varied according to the length of the idioms. The duration was determined by adding $40 \mathrm{msec}$ for each letter in a content word and $20 \mathrm{msec}$ for

Table 1

Median Idiomaticity and Meaning Similarity Ratings for Experiment 1 Materials

\begin{tabular}{|c|c|c|c|}
\hline Condition & $\begin{array}{c}\text { Idiom } \\
\text { Example }\end{array}$ & Idiomaticity & $\begin{array}{c}\text { Meaning } \\
\text { Similarity } \\
\text { to Standard }\end{array}$ \\
\hline $\begin{array}{l}\text { Standard idiom } \\
\text { Same meaning- }\end{array}$ & shoot the breeze & 4.3 & \\
\hline $\begin{array}{l}\text { same syntax } \\
\text { Different meaning- }\end{array}$ & chew the fat & 4.1 & 4.3 \\
\hline $\begin{array}{l}\text { same syntax } \\
\text { Different meaning- }\end{array}$ & raise the roof & 4.2 & 1.7 \\
\hline different syntax & nip and tuck & 4.2 & 1.9 \\
\hline
\end{tabular}

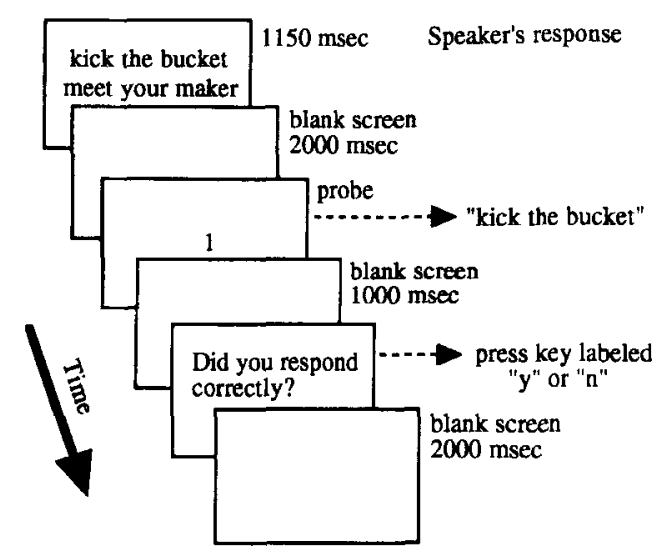

Figure 1. A representative experimental trial.

each letter in a function word to a base duration of $250 \mathrm{msec}$. This procedure was followed in order to allow speakers to read each idiom just once. The idiom pair was followed by a blank screen for $2 \mathrm{sec}$. Then a probe number (a 1 or 2 ) appeared in the center of the screen. The speaker's task was to recall aloud as quickly as possible one or the other idiom. If the probe number was 1 , the speaker was to recall the top idiom; if the probe number was 2 , the speaker recalled the bottom idiom. The probe number remained on the computer screen until a response had been made. At the voice-key trigger, the computer recorded the production latency of the response. If the speaker did not respond within $2 \mathrm{sec}$, the probe number disappeared and was replaced with a beep and a message telling the speaker to respond faster. One second after the voice-key trigger, a question appeared on the center of the screen asking, "Did you respond correctly?" The speaker's task was to press either a "Y" if they believed they had answered with the correct idiom and had said it correctly, or "N" for "No, I think that I made a mistake." 2 The next trial began $2 \mathrm{sec}$ after this response.

The filler trials had the same structure as the experimental trials, but the durations of the blank screens differed. The blank screen for half of the fillers had a 1-sec duration; for the other half, it had a 3 -sec duration. This was done to discourage the speakers from anticipating the onset of the probe number. An initial block of trials served as practice for the speakers, although they were not explicitly told that it was practice. There were 16 filler items in this block. These items were probed after delays representative of the items in the other blocks, five of the delays were $1 \mathrm{sec}$, five were $3 \mathrm{sec}$, and six were $2 \mathrm{sec}$.

Following the practice block, the remaining 56 filler pairs and 36 experimental pairs were presented in blocks of 23 items each. The order of items was random, with the constraint that at least one filler occur between any two experimental items. A single random order was used for all speakers, and all speakers received the same filler items.

The speakers were given a brief explanation of the procedure for a trial, along with examples that consisted of two complete trials displayed on a sequence of index cards. They were also instructed to respond as quickly as possible, without laughing, coughing, or making any unnecessary noises that would set off the voice key. They were told that they would be recorded on audio tape.

Design. Every speaker received one version of each experimental item, an equal number (12) in each of the three conditions. Within each condition, the order of idioms in each idiom pair and the probes for each pair were completely counterbalanced across speakers, yielding 12 distinct presentation sets. Every set was presented to 8 speakers so that 24 speakers received each version of every item (summing over the counterbalanced variations).

Scoring. The audio tapes were transcribed and the responses scored. Two raters independently scored each transcription. The re- 
sponses were classified into six mutually exclusive categories: (1) correct responses, (2) idiom blends, (3) intra-idiom errors, (4) intertrial errors, (5) complex errors, and (6) miscellaneous responses. Correct responses occurred when speakers correctly produced the probed idiom. Idiom blends were errors that combined elements from the two idioms in a single trial pair. Intra-idiom errors resulted from interference within a single idiom, while intertrial errors resulted from identifiable interference from any of the three previous trials. Complex errors consisted of intra-idiom or intertrial errors that involved more than one type of error (e.g., word addition and a substitution), errors that involved word blending or sound exchanges (e.g., shoot and throw produced show; and turn the tide and tip the scales produced turn the tides), and responses with an alternative idiom that shared a content word with the intended idiom (e.g., zip your lip presented but zip it up produced, when "it up" was not a part of the paired idiom or any of the preceding idioms). Miscellaneous responses were scored when the speaker produced the wrong idiom of a pair, an idiom from a previous trial, an incomplete idiom containing the word "something" (e.g., "kick the something"), or no response. Table 2 presents examples of each error type.

The three simple error types ( $2-4$ above) were further subcategorized into substitutions, additions, deletions, or movements. Substitutions and additions could be identified in all three error categories, but deletion and movement errors were relevant only in the intra-idiom category. Substitutions were errors in which a word was inserted in place of another word in the produced idiom (e.g., take to the woods produced as head to the woods). Additions were errors in which additional words were inserted without replacing any words (e.g., blow your top, produced as blow your top off). Deletions involved the omission of a word (e.g., hold a candle to, produced as hold a candle). Movements were errors in which the word order was changed (e.g., put down your foot, produced as put your foot down).

The application of these scoring criteria resulted in $81.3 \%$ corrects, $1.7 \%$ idiom blends, $4.9 \%$ intra-idiom errors, $1.3 \%$ intertrial errors, $2.7 \%$ complex errors, and $8.0 \%$ miscellaneous errors. There was $98.4 \%$ agreement between the two raters over all of the responses. The disagreements were discussed, re-evaluated, and then rescored according to the same set of criteria.

Separate one-way analyses of variance (ANOVAs) were performed on the data in each category. The error terms from these analyses were used to calculate $95 \%$ confidence intervals in order to perform Tukey tests. The first comparison contrasted the same-meaningsame-syntax condition with the different-meaning-same-syntax condition in order to assess the contribution of the figurative meaning. The second comparison contrasted the different-meaning-samesyntax with the different-meaning-different-syntax condition to assess the contribution of the syntactic structure. These contrasts were

Table 2

Examples of Error Categories for the Idiom Pair "Kick the Bucket" and "Meet Your Maker"

\begin{tabular}{|c|c|}
\hline Error Category & Example Errors \\
\hline \multicolumn{2}{|l|}{ Idiom blend } \\
\hline Addition & kick the bucket maker \\
\hline Substitution & kick the maker \\
\hline \multicolumn{2}{|l|}{ Intra-idiom } \\
\hline Addition & kick the bucket over \\
\hline Deletion & kick bucket \\
\hline Movement & bucket the kick \\
\hline Substitution & kick the rock \\
\hline \multicolumn{2}{|l|}{ Intertrial } \\
\hline Addition & kick the bucket around* \\
\hline Substitution & kick the millstone* \\
\hline Complex & kick the big rock \\
\hline Miscellaneous & kick the something \\
\hline
\end{tabular}

*The idiom millstone around your neck occurred in one of the previous three trials. performed over speakers and items. All effects at or beyond the .05 level were treated as significant, and those between .05 and .10 as marginally significant in this and both subsequent experiments.

\section{Results}

Production latencies. Times under $100 \mathrm{msec}$ were interpreted as false voice-key triggers and excluded from the analyses $(0.3 \%$ of the total). A further $3.8 \%$ of the trials were missing due to failure to meet the $2-\mathrm{sec}$ deadline. The mean production latencies for the remaining correct-response trials were $818 \mathrm{msec}$ for idiom pairs in the same-meaning-same-syntax condition, $785 \mathrm{msec}$ for idioms in the different-meaning-same-syntax condition, and $795 \mathrm{msec}$ for idioms in the different-meaningdifferent-syntax condition. These times are shown in Figure 2. A one-way ANOVA yielded an effect of condition that was significant by speakers $\left[F_{1}(2,95)=5.54, M S_{\mathrm{e}}=\right.$ $4,798]$ but not by items $\left[F_{2}(2,35)=2.70, M S_{\mathrm{e}}=3,695\right]$. Tukey tests were carried out on the condition differences with confidence intervals of $23 \mathrm{msec}$ by speakers and $34 \mathrm{msec}$ by items. For idiom pairs with the same syntax, those with the same meaning were slower (by $33 \mathrm{msec}$ ) than the pairs with different meanings, significantly so by speakers and marginally by items. For idioms with different meanings, the 10-msec difference between the production latencies for idiom pairs with same versus different syntax was not significant.

Error analyses. Table 3 shows the number of responses in each scoring category. The pattern of idiom blends is shown in Figure 2. Recall that these errors are a consequence of the substitution or addition of a word from one idiom for a word in the other idiom of the pair. Because only one addition occurred, we will focus on the substitutions. Most errors appeared in the same-meaning-samesyntax condition (29), followed by the different-meaningsame-syntax condition (20) and the different-meaningdifferent-syntax condition (9). ANOVAs demonstrated a significant effect of condition $\left[F_{1}(2,95)=6.10, M S_{\mathrm{e}}=\right.$ $\left.0.17 ; F_{2}(2,35)=3.34, M S_{\mathrm{e}}=0.84\right]$. Tukey tests were performed on the condition differences with $95 \%$ confidence intervals of 13.4 for speakers and 18.4 for items. The difference of 20 errors between the same-meaning-samesyntax condition and the different-meaning-differentsyntax condition was significant by both speakers and items. The 11 -error difference attributable to syntactic structure (contrasting the different-meaning-same-syntax and different-meaning-different-syntax conditions) was marginal by speakers $(90 \%$ confidence interval of 11.0 by speakers and 15.8 by items). There was no reliable effect of meaning in the comparison of the same-meaning-samesyntax and different-meaning-same-syntax conditions.

An ANOVA for the intra-idiom errors, collapsed across all of the subcategories, yielded a marginal effect of condition $\left[F_{1}(2,95)=2.84, M S_{\mathrm{e}}=0.49 ; F_{2}(2,35)=2.49\right.$, $\left.M S_{\mathrm{e}}=1.49\right]$, but the Tukey tests revealed no effect of syntax or meaning. For the intra-idiom substitution errors, the ANOVA yielded a significant effect of condition $\left[F_{1}(2,95)=4.94, M S_{\mathrm{e}}=0.41 ; F_{2}(2,35)=4.06, M S_{\mathrm{e}}=\right.$ 1.34]. The confidence intervals for the Tukey tests were 


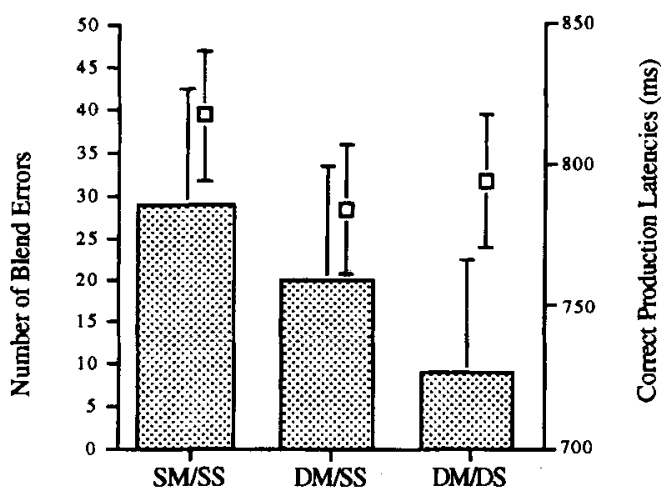

Figure 2. Correct response latencies and idiom blends in Experiment 1 . The three conditions are same meaning-same syntax (SM/SS), different meaning-same syntax (DM/SS), and different meaning-different syntax (DM/DS). The bars represent the blend errors, and the individual box points represent the naming times. The error bars reflect confidence intervals for the Tukey tests.

20.2 by speakers and 23.4 by items. The number of substitution errors in the different-meaning-different-syntax condition (56) was significantly larger than the number in the different-meaning-same-syntax condition (30). The test of the meaning difference was significant by speakers and marginal by items, with more errors when the paired idioms had the same meaning ( 52 vs. 30 ). There were relatively few errors in the intra-idiom addition, deletion, and movement subcategories, so we will not report analyses for these.

For the correct responses, the ANOVA yielded no significant differences between the conditions $\left[F_{1}(2,95)=\right.$ $\left.2.11, M S_{\mathrm{e}}=1.63 ; F_{2}(2,35)=1.21, M S_{\mathrm{e}}=6.75\right]$. Tukey tests showed no effect of meaning or syntax (confidence intervals were 41.3 by speakers and 52.6 by items). There were no differences among the errors in the intertrial or miscellaneous categories $(F \mathrm{~s}<1)$.

Within the complex error category, most of the errors occurred in the different-meaning-different-syntax condition (42), followed by the different-meaning-same-syntax condition (34) and the fewest in the same-meaning-samesyntax condition (18). The ANOVA yielded a significant effect of condition $\left[F_{1}(2,95)=4.17, M S_{\mathrm{e}}=0.37 ; F_{2}(2,35)\right.$ $\left.=3.19, M S_{\mathrm{e}}=1.30\right]$, but the Tukey tests disclosed no effect attributable to meaning or syntax (confidence intervals of 20.2 by speakers and 23.0 by items).

Qualitative analysis of the errors. The qualitative patterns of errors were similar across all three experiments, so we will only report them in detail for this experiment. For the sake of clarity, we will restrict the discussion to categories in which at least five errors occurred. These were the idiom blends, intra-idiom, and complex errors.

A breakdown of the blending errors showed that $93 \%$ ( 54 of 58) of the substituted words were of the same grammatical class as the word that they replaced. Of these, 20 involved prepositions, 19 involved the substitution of determiners, and 15 involved nouns or verbs. In the different-syntax condition, 6 of 9 of the substitution er- rors involved words of the same grammatical class and 4 of these 6 were words from different positions within the idioms. This helps to discount a positional interpretation of the grammatical class effect in the same-syntax condition. The remaining 3 errors in this condition involved substitutions of words that were not of the same grammatical class, and all of these involved words in the same position. Along with constraints observed on spontaneous blends, this suggests that grammatical class constrains idiomatic blending to some degree, with position perhaps playing a role in the experimental task as well.

Like the idiom blends, most of the intra-idiom substitution errors involved words of the same grammatical class ( $88.4 \%$ collapsed across the three conditions). Unlike the interidiom substitution errors, most of the intra-idiom errors involved nouns and verbs $(89.1 \%$ collapsed across the three conditions). Of these, $24.4 \%$ involved inflectional changes (e.g., wrap to wrapped), 56.9\% involved substitution of similar sounding words (not including the inflectional changes), $8.9 \%$ involved substitution of words related in literal meaning ( 3 of these were also in the similar-sound category), and $12.2 \%$ involved the substitution of some apparently unrelated word. The movement errors generally involved moving a preposition or a particle to the end of the phrase ( 7 of 9$)$. Most of the deletion errors involved leaving out a function word (11 of 14).

The complex errors $(n=94)$ consisted of multiple intraidiom substitution errors (52) or combinations of substitutions with additions (14), deletions (10), or movement errors (2). These errors were distributed fairly evenly across the three conditions. The remaining errors in this class stemmed from the production of an alternative idiom that shared part of the target idiom ( 8 errors, such as the replacement of zip it up with zip your lip) or blends between words from each idiom (one in each condition).

Table 3

Number of Correct Responses and Distribution of Errors in Experiment 1

\begin{tabular}{lccc}
\hline & \multicolumn{3}{c}{ Condition } \\
\cline { 2 - 4 } Scoring Category & SM/SS & DM/SS & DM/DS \\
\hline Correct & 951 & 942 & 916 \\
Miscellaneous & 80 & 96 & 101 \\
Complex & 18 & 34 & 42 \\
& Idiom Blends & & \\
Addition & $0[0]$ & $0[0]$ & $1[0]$ \\
Substitution & $29[10]$ & $20[2]$ & $9[4]$ \\
& Intra-Idiom Errors & \\
Addition & $3[1]$ & $4[3]$ & $0[0]$ \\
Deletion & $0[0]$ & $6[2]$ & $8[1]$ \\
Movement & $5[0]$ & $3[0]$ & $1[1]$ \\
Substitution & $52[44]$ & $30[28]$ & $56[51]$ \\
& Intertrial Errors & \\
Addition & $0[0]$ & $1[0]$ & $4[1]$ \\
Substitution & $14[3]$ & $16[3]$ & $14[3]$ \\
\hline
\end{tabular}

Note - SM $/ \mathrm{SS}=$ same meaning-same syntax, DM/SS $=$ different meaning-same syntax, DM/DS = different meaning-different syntax. Values in square brackets are the number of errors involving content words. 


\section{Discussion}

The results of Experiment 1 suggest that the production of an idiomatic blend is somewhat sensitive to the internal syntactic structure and to the figurative meaning of the idioms involved. Idioms from pairs with similar figurative meanings were more slowly produced than idioms with different figurative meanings, and idioms with the same syntactic structure were more likely to blend together than those with different syntactic structures.

To examine whether the figurative meaning effect could be traced to literal similarity, the idiom pairs from the same-meaning-same-syntax condition were divided into two groups, (1) those that were intuitively different in literal meaning $(n=27)$, and (2) those that were similar $(n=9)$. The different-literal idioms took $22 \mathrm{msec}$ longer in the same-meaning-same-syntax condition than in the different-meaning-same-syntax condition and accounted for $56 \%$ of the idiom blends. The same-literal idioms took $42 \mathrm{msec}$ longer. So, although it appears that literal similarity enhanced the meaning effect (something that Experiment 2 examines in greater detail), figurative similarity played a part too.

The pattern of idiom blends (e.g., kick the maker) revealed an effect of the idioms' syntax. Idiom pairs with the same form tended to blend more than pairs with different forms. This reflects a general feature of speech errors: interacting elements tend to be similar to one another. Stemberger (1985) reported that $99.7 \%$ of the noncontextual errors (phonological or semantic substitutions) in his error corpus obeyed the grammatical category constraint. In the idiom blends, $93 \%$ involved the substitutions of words from the same grammatical class. The rate expected by chance was $29 \%$.

Turning to the intra-idiom errors (e.g., kick the rock), we see a similar grammatical category constraint, with $88 \%$ of the substitutions involving words of the same grammatical category. In other ways, however, the error distribution differed from that for blends. Among the intraidiom errors, there were more substitutions for idiom pairs with similar meanings and fewer for idiom pairs with the same structure, while for blends, syntactic similarity resulted in more errors. This difference may reflect the nature of the two error types. When the paired idioms had different structures, there was less support from the syntax due to the absence of structural repetition (Bock, 1990). This may allow for the intrusion of lexical items that were semantically or phonologically similar. But when the paired idioms had the same structure, structural repetition supported and maintained the components of the two idioms in integrated structures.

Taken together, the influence of syntactic form and the involvement of grammatical class argue against the strong unitization hypothesis. Idioms are not produced as "frozen phrases" in which the components lose all of their individual word-like properties. Instead, they are syntactically analyzed.

\section{EXPERIMENT 2}

A subsidiary finding in Experiment 1 suggested that the literal meanings of idioms might enhance their participation in errors. The second experiment was designed expressly to see whether the literal meanings of idioms were active during production.

The literal and figurative meanings of idioms play distinct roles within the standard pragmatic hypothesis, the unitization hypothesis, and the direct access hypothesis. All of these maintain that the literal meaning is used in some way during comprehension. However, the role of literal meaning may be quite different in production. A listener begins with the task of trying to resolve an incoming stream of words, while a speaker begins with the conceptual content. The comprehender must decide whether the literal or figurative interpretation of the phrase is appropriate. The speaker, knowing what is to be conveyed, should access the idiom through its idiomatic meaning without mediation from the literal meaning. For example, a speaker intending to convey that [Howard died] should be able to activate "Howard kicked the bucket" without first accessing a literal meaning along the lines of "Howard punted the pail." However, Cacciari and Glucksberg (1991) have argued that the literal meaning of an idiom is critical for use in discourse. This implies that the literal meaning of an idiom must be accessible at some point during production.

The present experiment examined whether literal meaning affects idiom production. If idiom production is independent of literal meaning, then there should be no influence of an idiom's literal meaning on the production of idiom errors. On the other hand, if the literal meaning of an idiom does play a role in its use, one would expect to see perturbations from literal-meaning similarity in the production of errors.

Four pairings of phrases were used: (1) A standard idiom and a literal phrase with the same literal meaning as the standard (hold your tongue; grab your lip), (2) the standard idiom and a phrase with a different literal meaning (hold your tongue; sign your name), (3) the standard idiom and an idiom with the same figurative meaning but a different literal meaning (hold your tongue; button your lip), and (4) the standard idiom and an idiom with a different figurative meaning and a different literal meaning (hold your tongue; flip your lid). All of them had the same syntactic structure. The critical comparisons are tested in the first two conditions, those with literal phrases. If the literal meaning of an idiom is available during production, a phrase with a similar literal meaning should participate in more blends than the paired phrase with a different literal meaning. The last two conditions correspond to the same-meaning-samesyntax and different-meaning-same-syntax conditions in Experiment 1 , and provide a baseline for the contribution of figurative meaning. 


\section{Method}

Participants. Ninety-six different undergraduates from the same source as the previous experiment participated in this experiment; 18 speakers were replaced for the same reasons as in Experiment 1. All were native speakers of English.

Materials. Thirty-two same-meaning-same-syntax idiom pairs were selected from the stimuli used in Experiment 1. For the standard idiom in each pair, a paraphrase of its literal meaning was created by substituting two (in 30 instances) or three (in 2 instances) of the words in the idiom with words of similar meaning. Each standard idiom was also paired with an unrelated literal phrase. All of the related and unrelated literal phrases had the same syntactic structure as their paired standard idioms. The complete set of experimental items is presented in the Appendix.

In addition to the experimental idioms, there were 80 practice and filler items. Of these, 40 were pairs of idioms with different figurative meanings and 40 were pairs consisting of one idiom and one literal phrase with different literal meanings. The members of all of these pairs differed in syntactic form (but had the same number of words).

Each list contained 32 experimental and 80 filler items. The 112 pairs were broken into five blocks, with the first block, consisting of 16 filler items, serving as a practice block. Each of the remaining four blocks consisted of 8 experimental and 16 fillers randomly distributed with the constraint that there was always at least one filler item between any two experimental items.

Design. Crossing meaning type (figurative or literal) and similarity of meaning (similar or different meaning) yielded four conditions. In the figurative-meaning conditions, both items of the pair consisted of idioms with either similar or different figurative meanings. In the literal-meaning conditions, the pair consisted of one idiom and one literal phrase, with either similar or different literal meanings. Note that the type of meaning that is similar in the figurative-meaning condition is the figurative meaning and in the literal-meaning condition is the literal meaning. An example of an experimental pair in each condition is given in Table 4. As in Experiment 1 , probe number and pair order were completely crossed with these conditions. This resulted in 16 counterbalanced lists, each containing eight items in each of the four conditions, with two items of each type in each of the four probe/order conditions. Across lists, every item appeared once in each of the conditions.

Procedure. The procedure was the same as in Experiment 1.

Scoring. The scoring criteria were identical to those in the first experiment. The scoring yielded $83.4 \%$ corrects, $1.8 \%$ interidiom errors, $5.2 \%$ blend errors, $1.9 \%$ intertrial errors, $2.0 \%$ complex errors, and $5.8 \%$ miscellaneous errors. There was $97.9 \%$ agreement of scores between the two raters over all of the responses.

Separate two-way (meaning type $\times$ similarity of meaning) ANOVAs were performed on each scoring category by speakers and items.

\section{Results}

Production latencies. The production latencies for correct responses in each condition are shown in Figure 2. There was an effect of meaning type such that phrases in the figurative conditions (consisting of idiom

\section{Table 4}

Examples of the Idiom Pairs Used in the Conditions of Experiment 2

\begin{tabular}{lll} 
& \multicolumn{2}{c}{ Meaning Type } \\
\cline { 2 - 3 } Meaning Similarity & \multicolumn{1}{c}{ Figurative } & \multicolumn{1}{c}{ Literal } \\
\hline Similar meanings & $\begin{array}{l}\text { hold your tongue } \\
\text { button your lip } \\
\text { hold your tongue }\end{array}$ & $\begin{array}{l}\text { hold your tongue } \\
\text { grab your lip } \\
\text { hold your tongue } \\
\text { flip your lid }\end{array}$ \\
\hline
\end{tabular}

pairs) were produced faster than phrases from the literal conditions (consisting of idiom-literal-phrase pairs), 765 and $784 \mathrm{msec}$, respectively. This difference was significant by both speakers and items $\left[F_{1}(1,95)=4.89\right.$, $\left.M S_{\mathrm{e}}=7,091 ; F_{2}(1,31)=4.33, M S_{\mathrm{e}}=2,560\right)$. There was no difference between phrases in similar-meaning versus different-meaning pairs ( 775 vs. $774 \mathrm{msec}$, all $F$ s $<1.0$ ). The interaction between meaning type and meaning similarity was also not significant $\left[F_{1}(1,95)=2.27, M S_{\mathrm{e}}=\right.$ 6,$\left.651 ; F_{2}(1,31)=0.03, M S_{\mathrm{e}}=4,451\right]$.

Error analyses. Table 5 shows the number of responses in each scoring category. The pattern of idiom blends is shown in Figure 3. There was an overall effect of meaning similarity for blend errors. Phrase pairs with the same meaning (either literal or figurative) produced significantly more blend errors than did pairs with different meanings $\left[F_{1}(1,95)=5.72, M S_{\mathrm{e}}=0.13 ; F_{2}(1,31)=6.37\right.$, $\left.M S_{\mathrm{e}}=0.36\right]$. There was no main effect of meaning type, and nor did the meaning type $\times$ meaning similarity interaction reach statistical reliability $\left[F_{1}(1,95)=1.67, M S_{\mathrm{e}}=\right.$ $\left.0.13 ; F_{2}(1,35)=1.44, M S_{\mathrm{e}}=0.44\right]$.

There were twice as many complex errors in the figurative conditions (those with paired idioms) as in the literal conditions (those with paired idioms and literal phrases), 40 to 20 . This result yielded a significant main effect of meaning type by speakers $\left[F_{1}(1,95)=5.67, M S_{\mathrm{e}}=\right.$ $0.18]$ and marginal by items $\left[F_{2}(1,31)=3.97, M S_{\mathrm{e}}=\right.$ $0.79]$.

The analyses of correct responses, intra-idiom, intertrial, and miscellaneous errors detected no significant differences attributable to meaning type or meaning similarity; nor were there significant interactions between the two factors.

\section{Discussion}

The most important result from this study was that literal-meaning similarity between an idiom and a phrase produced as many errors as did figurative-meaning similarity. Underscoring this is the fact that more than half of the errors occurred on content words. Since content words carry the burden of the meaning, this finding implies that the errors reflect a tendency for similar meanings (either literal or figurative) to interact. Finally, the tendency for blending errors to obey the grammatical class constraint held in both the figurative and literal conditions, suggesting that this constraint is blind to whether the blending phrases are idioms. All of these findings offer evidence that literal meaning is active during the production of idioms, consistent with Cacciari and Glucksberg's (1991) contention that the literal meaning of an idiom is involved in their productive use in discourse.

One objection to these results is that the speakers may have ignored the figurative meanings of the idioms and focused on the literal meanings. However, there are reasons to believe otherwise. The figurative phrases were produced faster than the literal phrases, paralleling many of the findings in the comprehension literature. And there were more blends in the same-figurative - differentliteral meaning condition than in the different-figurative- 
Table 5

Number of Correct Responses and Distribution of Errors in Experiment 2

\begin{tabular}{lcccc}
\hline & \multicolumn{4}{c}{ Meaning Condition } \\
\cline { 2 - 5 } Scoring Category & \multicolumn{2}{c}{ Literal } & \multicolumn{2}{c}{ Figurative } \\
\cline { 2 - 5 } \cline { 3 - 5 } Correct & Similar & Different & Similar & Different \\
Miscellaneous & 635 & 663 & 633 & 631 \\
Complex & 44 & 38 & 50 & 45 \\
& 11 & 9 & 17 & 23 \\
Addition & \multicolumn{1}{c}{ Idiom Blends } & & \\
Substitution & $0[0]$ & $0[0]$ & $0[0]$ & $0[0]$ \\
& $18[15]$ & $5[1]$ & $18[8]$ & $14[2]$ \\
Addition & Intra-Idiom Errors & & \\
Deletion & $2[0]$ & $2[1]$ & $0[0]$ & $9[7]$ \\
Movement & $5[0]$ & $2[0]$ & $2[0]$ & $5[1]$ \\
Substitution & $0[0]$ & $1[0]$ & $1[0]$ & $0[0]$ \\
& $40[33]$ & $30[19]$ & $34[25]$ & $28[20]$ \\
Addition & Intertrial Errors & & \\
Substitution & $1[1]$ & $1[0]$ & $2[0]$ & $0[0]$ \\
\hline
\end{tabular}

Note - Values in square brackets are the number of errors involving content words. Literal refers to the conditions consisting of an idiom and a literal phrase. Figurative refers to the conditions consisting of two idioms.

different-literal meaning condition, replicating Experiment 1 . This is most evident in the content word errors. The implication is that the speakers processed the figurative as well as the literal meanings.

\section{EXPERIMENT 3}

Experiment 3 was designed with a different dimension of idiomatic meaning in mind. Gibbs and Nayak (1989) demonstrated that speakers' intuitions about the decomposability of an idiom are correlated with the idiom's syntactic flexibility. In decomposable idioms, the lexical parts of the idiom map onto distinguishable meaning components. Decomposable idioms may thus be less rigidly encoded in the lexicon than nondecomposable idioms. For the purposes of the experiment proposed here, this leads to the prediction that decomposable idioms may be more susceptible than nondecomposable idioms to the production of idiom blends.

As in Experiment 1, same-meaning-same-syntax idiom pairs were created. The pairs consisted of either decomposable or nondecomposable idioms, as determined from decomposability ratings. The syntactic structure and figurative meanings of the idiom pairs were the same, leaving any differences in the error pattern attributable to decomposability alone. If the lexical representation of decomposable idioms is less rigidly specified and more susceptible to change (Gibbs \& Nayak, 1989), they should be more predisposed to blending than nondecomposable idioms, if the latter tend to be lexically frozen.

\section{Method}

Participants. The participants in this experiment were 80 different undergraduates drawn from the same source as Experiments 1 and 2. Sixteen were replaced due to problems with the voice key or with reading the idioms. All were native speakers of English.
Materials. The idiom pairs were created from a set of idioms that were rated for decomposability. The rating procedure was adapted from Gibbs and Nayak (1989). Twenty-six judges received a list of 141 idioms and a paraphrase of their idiomatic meaning (e.g., "Chew the fat: To talk casually"). The judges were asked to rate on a 5-point scale how analyzable they thought the idiom was. The instructions explained the nature of a decomposable relationship between an idiom's words and its figurative meaning in terms of an example (pop the question) and contrasted this with a nondecomposable idiom (give the bounce). The ratings were made on a 5-point scale, on which 1 was nondecomposable and 5 was decomposable.

Included in the rated idioms were the 72 idioms from the samemeaning-same-syntax condition of Experiment 1. From these 36 pairs, 10 pairs in which both idioms were relatively decomposable and 10 pairs in which both idioms were relatively nondecomposable were selected as the experimental items for the third experiment. These items and their decomposability ratings are presented in the Appendix. The median rating of the idioms used in the decomposable pairs was 3.5 (range 3.1 to 4.2 ); for nondecomposable pairs, it was 2.3 (range 1.7 to 2.9 ). The mean differences between the decomposability ratings for the paired idioms were 0.04 for the decomposable pairs and 0.03 for nondecomposable pairs. The mean same/ different figurative meaning ratings (see Experiment 1 ) were 4.5 for the decomposable pairs and 4.0 for the nondecomposable pairs.

In addition to the 20 experimental items, 40 filler items were created. Like the experimental items, these items were idiom pairs with the same meaning and same syntax. Ten items were same-meaningsame-syntax pairs from Experiment 1 , in which one idiom had been rated as decomposable and the other as nondecomposable. The remaining 30 pairs were made up of idioms with different meanings.

The 60 items were grouped into three blocks of trials. The first block, which consisted of 10 fillers, served as practice. The remaining two blocks each had 25 idiom pairs ( 10 experimental items and 15 fillers) which were ordered with the constraint that there was always at least one filler item between any two experimental items.

Design. The idiom pairings yielded two conditions, decomposable versus nondecomposable idioms. As in Experiments 1 and 2, probe number and idiom-pair order were completely crossed with these conditions. This created four counterbalanced lists, each containing 10 different pairs from each experimental condition.

Procedure. The procedure was identical to that of the previous experiments.

Scoring. The same scoring criteria were applied. This resulted in $81.1 \%$ corrects, $3.6 \%$ idiom blends, $5.8 \%$ intra-idiom errors, $0.7 \%$

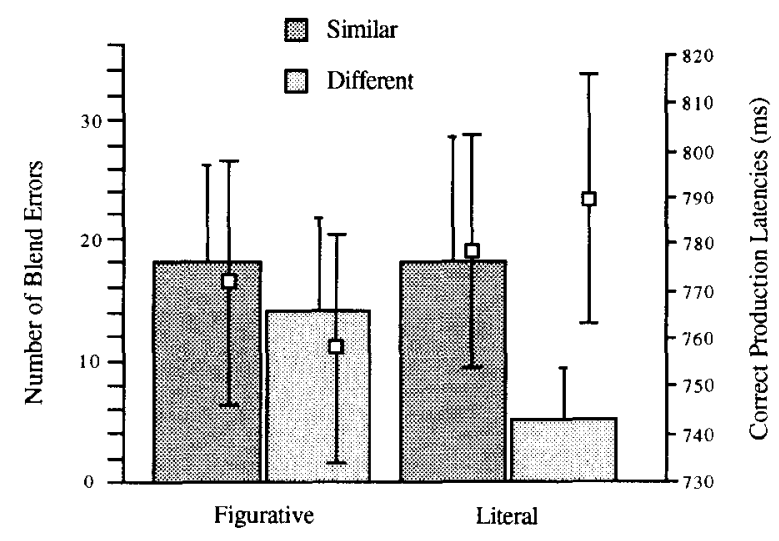

Meaning Type

Figure 3. Correct-response latencies and idiom blends in Experiment 2 . The bars represent the blend errors and the individual box points represent the naming times. The error bars reflect confidence intervals for the Tukey tests. 
intertrial errors, $1.8 \%$ complex errors, and $7.0 \%$ miscellaneous errors. There was $99.2 \%$ agreement between the two raters over all of the responses.

One-way repeated measures ANOVAs were computed for the error and production-latency data, with speakers as the random factor $\left(F_{1}\right)$, and one-way between-groups ANOVAs were computed with items as the random factor $\left(F_{2}\right)$.

\section{Results}

Production latencies. The production latencies for correct responses are shown in Figure 4. The naming times were slightly faster for decomposable idiom pairs (791 $\mathrm{msec}$ ) than for nondecomposable pairs (804), but the difference was not statistically reliable $\left[F_{1}(1,79)=\right.$ $\left.1.15, M S_{\mathrm{e}}=5,959 ; F_{2}(1,18)=1.43, M S_{\mathrm{e}}=1,637\right]$. Using the $M S_{\mathrm{e}}$ from the ANOVA as an estimate of the population variance, we estimated that this experiment could have detected a 34-msec difference with a power of .80 . This difference is comparable to the significant difference found in Experiment 1.

Error analyses. Table 6 shows the number of responses in each scoring category. The ANOVA detected no difference between the conditions in numbers of correct responses or errors, except in the miscellaneous error category. Nondecomposable idiom pairs produced more miscellaneous errors than did decomposable pairs, significantly so by speakers but not by items [68 vs. 45 ; $F_{1}(1,79)=7.41, M S_{\mathrm{e}}=0.49 ; F_{2}(1,18)=1.05, M S_{\mathrm{e}}=$ 27.4]. The pattern of idiom blends is shown in Figure 4. Using the $M S_{\mathrm{e}}$ from the ANOVA as an estimate of the population variance, we estimated that the experiment could have detected a difference of 17 blend errors with a power of .80 . This difference is comparable to the significant 20-error difference found in Experiment 1.

\section{Discussion}

The predicted differences in the error rates between the decomposable and nondecomposable pairings did not materialize. This suggests that the lexical representations of decomposable and nondecomposable idioms are the same when they enter into the production process, and

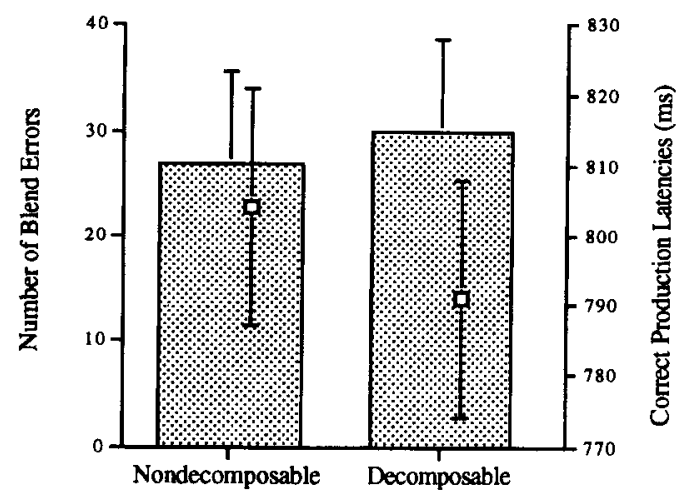

Figure 4. Correct-response latencies and idiom blends in Experiment 3. The bars represent the blend errors and the individual box points represent the naming times. The error bars reflect confidence intervals for the Tukey tests.
Table 6

Number of Correct Responses and Distribution of Errors in Experiment 3

\begin{tabular}{lcc} 
& \multicolumn{2}{c}{ Decomposability Classification } \\
\cline { 2 - 3 } Scoring Category & Nondecomposable & Decomposable \\
\hline Correct & 641 & 657 \\
Miscellaneous & 68 & 44 \\
Complex & 17 & 13 \\
& Idiom Blends & \\
Addition & $0[0]$ & $0[0]$ \\
Substitution & $27[7]$ & $30[4]$ \\
& Intra-Idiom Errors & \\
Addition & $0[0]$ & $2[0]$ \\
Deletion & $2[1]$ & $3[0]$ \\
Movement & $1[1]$ & $0[0]$ \\
Substitution & $40[40]$ & $45[41]$ \\
& Intertrial Errors & \\
Addition & $0[0]$ & $1[0]$ \\
Substitution & $6[1]$ & $5[0]$ \\
\hline
\end{tabular}

Note -. Values in square brackets are the number of errors involving content words.

supports a weak version of the unitization hypothesis over the decomposability hypothesis.

To ensure that the null result could not be attributed to norming disparities, we compared ratings for overlapping items in the published literature (Gibbs, 1987; Gibbs \& Nayak, 1989; Gibbs, Nayak, Bolton, \& Keppel, 1989; Gibbs, Nayak, \& Cutting, 1989). Of the items in the present experiment, there were six used by Gibbs and his colleagues. All were in agreement. Three of the items were rated as nondecomposable in Gibbs's work and by our judges and three items were rated as decomposable in both sets of materials. So, although the number of overlapping items is not large, the convergence is reassuring.

The single difference obtained in this experiment was that nondecomposable idiom pairs produced more miscellaneous errors. If nondecomposable idioms are harder to understand and remember than decomposable idioms, these errors would stem from memory failure. This is the same result that Gibbs and Gonzales (1985) reported. They presented participants with short stories that ended in either a syntactically frozen idiom, a syntactically flexible idiom, or a literal phrase. The participants' task was to recall the final sentence of each story corresponding to a cue. The flexible idioms were recalled more often than the frozen idioms ( $46 \%$ vs. $32 \%$ ), implying that nondecomposable idioms are more difficult to remember. These results offer further evidence that the decomposable idioms in the present experiment differed in the relevant properties.

\section{GENERAL DISCUSSION}

The experiments presented here offer a new kind of evidence for the view that idioms are compositional. Across all three experiments, idiom blend errors consistently involved structurally and semantically similar components. Like literal phrases, idioms fall apart along 
linguistically sensible lines. Apparently, idioms are not lexicalized chunks, comparable to large single words, but phrases with internal syntactic and semantic components. Among these components, there are some that provide access to an idiom's literal meaning during language production.

The first experiment suggested that the production of idioms was sensitive to their internal syntactic properties. Idioms with the same syntactic structures were more likely than idioms with different structures to interfere with one another, resulting in a greater number of blends in the idioms with the same structures. Additionally, substitution errors tended to obey a grammatical category constraint. These results argue against the unitization hypothesis (Swinney \& Cutler, 1979), suggesting instead that idiomatic representations include syntactic information.

In the results for production latencies, Experiment 1 further suggested that idioms with similar figurative meanings tend to interfere with each other. The second experiment went beyond this to examine the influence of an idiom's literal meaning on its blending behavior. The results indicated that the literal meanings of idioms might be active during production, consistent with the claims of Cacciari and Glucksberg (1991). Phrases with similar meanings produced more blending errors than did phrases with dissimilar meanings, regardless of whether the meaning similarity was literal or figurative.

If we assume that idioms are stored phrases with constituent parts, something must be said about the nature of the individual parts. The final experiment explored the role of an idiom's decomposability during production. Decomposability refers to the assumptions that speakers make about how the meanings of the parts of an idiom contribute to the idiom's meaning as a whole, and ratings of decomposability are correlated with judgments of syn- tactic flexibility. However, in Experiment 3 decomposable idioms blended together at the same rate as nondecomposable idioms, suggesting that the components of decomposable and nondecomposable idioms are accessed similarly during production.

This result contrasts with the outcome of studies by Gibbs, Nayak, and Cutting (1989). They presented participants with strings of words and asked whether they were meaningful English phrases. Half of the meaningful items were idioms and the other half were literal phrases. Responses to nondecomposable idioms were slower than those to decomposable idioms. Gibbs et al. proposed that during comprehension, parts of the idiomatic meaning are distributed over the components of the idiom. For example, in interpreting the decomposable idiom spill the beans, a comprehender recognizes that each component can be assigned an independent meaning, and understands how it contributes to the whole. However, for a nondecomposable idiom like kick the bucket, the comprehender attempts to assign independent meanings to the parts but cannot, leading to a slower response.

For language production, the story may be different because the producer starts with the ideas to be communicated. That is, the production system begins with a thought and then constructs an utterance to convey it. A language production model like that developed in Dell (1986; a similar model might be constructed from the model developed in Levelt, 1989) offers an explicit framework for explaining how this proceeds. Figure 5 provides a sketch.

In the model, there is a distinction between syntax and the lexicon. The syntactic part of the model consists of a set of rules that create a structural frame. The terminal nodes of these frames are grammaticality categorized siots. The lexicon consists of a network of nodes for linguistic units such as concepts, words, morphemes, and phonemes.

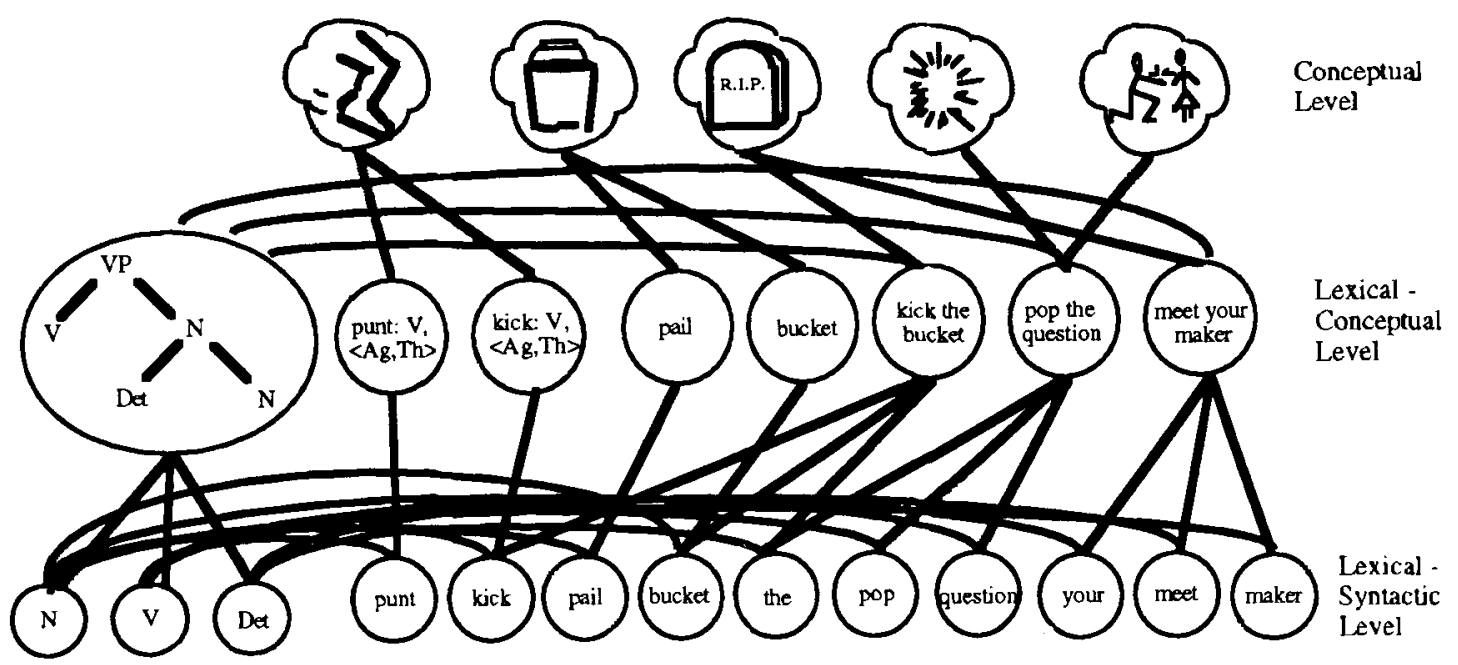

Figure 5. A model of the lexicon, including representations for the idioms pop the question and kick the bucket. 
The conceptual nodes are connected to the word nodes, the word nodes to the morphemes, and so on. The cross talk between the syntactic frames and the lexicon occurs within each level. For example, at the lexical level, insertion rules select activated lexical items from the lexicon to fill the slots in the syntactic frame. The lexical item assigned to a slot must be of the grammatical type that a slot specifies.

Let us suppose that the lexicon has nodes representing idioms as wholes. These nodes are situated between the conceptual and lexical layers of nodes, so we will refer to them as lexical-concept nodes (following Roelofs, 1992). These lexical-concept nodes are associated with the syntactic portion of the system, and can retrieve phrasal frames that specify the ordering of grammatical slots rather than single lexical categories. That is, the lexical representation of an idiom (e.g., kick the bucket) is associated with a phrasal node (a verb phrase) in the syntactic part of the system, not to a single grammatical category (e.g., verb). In terms of the models of idiom representation presented here, this corresponds to the difference between the weak and strong versions of the unitization hypothesis.

In the lexicon, an idiom's lexical-conceptual node is also associated with lexical nodes (lemmas) corresponding to its component parts. That is, the representation of an idiom like kick the bucket is associated with individual lemmas (kick, the, and bucket). A lemma is a representation of a word that is associated with its grammatical class (Roelofs, 1992). On this view, the decomposability of an idiom is related to the way in which lexical-conceptual representations are associated to conceptual representations. If an idiom is conceptually decomposable, there will be multiple links between the lexical-conceptual and conceptual levels, while a nondecomposable idiom will have a single association between the two levels. For example, in Figure 4, the lexical-conceptual node for kick the bucket is linked to the single conceptual node died, while the node for pop the question is linked to the conceptual nodes for both suddenly and to propose.

This model predicts that in production, nondecomposable idioms will be as syntactically flexible as decomposable idioms. Once the lexical-conceptual representation of an idiom has been selected (through activation from the conceptual nodes), syntactic production processes are indifferent to an idiom's decomposability, implying that speakers should be as likely to vary the form of a nondecomposable idiom as a decomposable one. Although comprehension studies have demonstrated that nondecomposable idioms are more difficult to comprehend after structural transformation than decomposable idioms (Gibbs \& Nayak, 1989), the question has not yet been addressed in production.

In terms of the model sketched above, the increase in error production when idioms have the same figurative meaning can be seen as a consequence of similar conceptual representations, creating more competition than dissimilar conceptual representations. Note that the relationship between the conceptual level and the lexical- conceptual level of two idioms with similar figurative meanings (e.g., kick the bucket and meet your maker) is comparable to the relationship between the conceptual and lexical-conceptual levels for two words with similar literal meanings (e.g., bucket and pail). Thus, the increase in error production that occurred when an idiom was paired with a literally similar phrase may arise as a consequence of shared conceptual representations.

The model also shows how the increase in blending errors that occurred when idioms had the same syntactic form may result from sharing the same syntactic representation. In the model, the grammatical class restriction is a consequence of the insertion rules that are responsible for the interaction between the lexical and syntactic parts of the system. The influence of literal meaning arises from competition between related lexical nodes that are activated by the idiomatic representation.

Before we conclude, there are several concerns to be addressed about the results of the present experiments. The first is the possibility that the errors that occurred were not production errors but reading errors, slips of the eye rather than slips of the tongue. In an attempt to distinguish these two potential sources of error, speakers were asked after each trial whether they had responded correctly, on the assumption that if speakers were aware that they had made an error it was safe to conclude that the error was in speech rather than in reading. The pattern of these "pure production" errors was similar to the overall distribution, but their numbers were too small to permit formal analysis. Table 7 presents these pure production errors for all three experiments. Although it is possible that the balance of the errors arose in reading, a more plausible interpretation is that error detection was difficult. In one of very few studies to examine detection rates, Levelt (1983) reported that only $46 \%$ of color-word errors were repaired in a task that required color naming. Levelt concluded that this was due to failures in the detection of errors by the speakers.

Another concern relates to our focus on idiom representation and production. Because the task had an inher-

Table 7

Comparison of All the Idiom Blends and the Pure Production Idiom Blends in All of the Experiments

\begin{tabular}{ccc}
\hline & All & Pure \\
& Idiom & Production \\
Experimental Condition & Blends & Blends \\
\hline
\end{tabular}

Experiment 1

Same meaning/same syntax

Different meaning/same syntax

Different meaning/different syntax

29

Experiment 2

$\begin{array}{lrl}\text { Similar literal meaning } & 18 & 4 \\ \text { Different literal meaning } & 5 & 0 \\ \text { Similar figurative meaning } & 18 & 5 \\ \text { Different figurative meaning } & 14 & 1\end{array}$

Experiment 3

Nondecomposable 27 Decomposable 30 
ent comprehension component, the results could reflect comprehension more than production processes. There are three reasons to discount this possibility. First, there was a close parallel between the overall error pattern and the "pure production" errors for which the speakers identified their slips as production errors. The second argument against the comprehension explanation is the lack of any effects of decomposability in Experiment 3. This is at odds with results in the idiom-comprehension literature (Gibbs \& Gonzales, 1985; Gibbs \& Nayak, 1989). The last argument stems from a finding by Lombardi and Potter (1992), which showed that short-term memory tends to be meaning-based even after a very short delay. Recall is based on the meaning of the utterance, expressed through normal production processes. Their results suggest that the utterances produced after the $2-\mathrm{sec}$ delay in the present experiments were likely to have involved normal production processes.

Taken together, these points suggest that the comprehension contamination of the experimental measures was minimal. Of course, these effects cannot be completely ruled out and some aspects of our results may be more readily explained in terms of comprehension processes. One is the literal meaning effect in the second experiment. Cacciari and Tabossi (1988) showed that, once a phrase is identified as an idiom, literal processing is halted and the literal interpretation is lost. This challenges the interpretation that literal meaning had its impact during production.

A final concern is the relative weakness of the effects. The task that we used produced very small differences in errors and production latencies. This is an unfortunate but unsurprising consequence of the highly practiced nature of normal production and the resulting rarity of speech errors. Still, as a vehicle for a preliminary exploration of the representation of idioms by speakers, the method has decided advantages over the observation of naturally occurring errors.

In conclusion, these experiments suggest that idioms are not produced as "frozen phrases," devoid of information about their internal syntax and semantics. As others have argued from studies of comprehension (Cacciari \& Glucksberg, 1991; Gibbs \& Gonzales, 1985; Gibbs \& Nayak, 1989), idiom representations are linked to information about the grammatical class of their constituents, about their overall syntactic structures, and about literal meaning. Within the model sketched above, idioms are idioms because of how they are associated to conceptual representations, as well as how they are represented in the lexicon. Idioms may be special in their relationships to nonlinguistic concepts, but they are not special in the way they are produced in normal language use.

\section{REFERENCES}

BAARS, B. J. (1980a). The competing plans hypothesis: An heuristic viewpoint on the causes of errors in speech. $\ln \mathrm{H}$. W. Dechert \& D. A. Raupach (Eds.), Temporal variables in speech (pp. 39-49). New York: Mouton.

BAARS. B. J. (1980b). On eliciting predictable speech errors in the laboratory. In V. A. Fromkin (Ed.), Errors in linguistic performance:
Slips of the tongue, ear, pen and hand (pp. 307-318). New York: Academic Press.

BoBrow, S. A., \& BelL, S. M. (1973). On catching on to idiomatic expressions. Memory \& Cognition, 1, 343-346.

Bock, J. K. (1990). Structure in language: Creating form in talk. American Psychologist, 45, 1221-1236.

BUTTERWORTH, B. L. (1982). Speech errors: Old data in search of new theories. In A. Cutler (Ed.), Slips of the tongue and language production (pp. 73-108). Amsterdam: Mouton.

Cacciari, C., \& Glucksberg, S. (1991). Understanding idiomatic expressions: The contribution of word meanings. In G. B. Simpson (Ed.), Understanding word and sentence (pp. 217-240). Amsterdam: North-Holland.

Cacciari, C., \& TABossi, P. (1988). The comprehension of idioms. Journal of Memory \& Language, 27, 668-683.

DELL, G. S. (1986). A spreading activation theory of retrieval in language production. Psychological Review, 93, 283-321.

DeLL, G. S., \& ReICH, P. A. (1981). Stages in sentence production: An analysis of speech error data. Journal of Verbal Learning \& Verbal Behavior, 20, 611-629.

DIK, S. C. (1989). Idioms in a computational functional grammar. In M. Everaert \& E. Van der Linden (Eds.), Proceedings of the first Tilburg workshop on idioms (pp. 41-55). Tilburg: ITK Proceedings.

FAY, D. (1982). Substitutions and splices: A study of sentence blends. In A. Cutler (Ed.), Slips of the tongue and language production (pp. 163-195). Amsterdam: Mouton.

Fraser, B. (1970). Idioms within a transformational grammar. Foundations of Language, 6, 22-42.

Fromkin, V. A. (1971). The non-anomalous nature of anomalous utterances. Language, 47, 27-52.

Fromkin, V. A. (1973). Speech errors as linguistic evidence. The Hague: Mouton.

GARRETT, M. F. (1980). Levels of processing in sentence production. In B. L. Butterworth (Ed.), Language production (Vol. 1, pp. 177-220). New York: Academic Press.

GrBBS, R. W. (1984). Literal meaning and psychological theory. Cognitive Science, 8, 275-304.

GIBBS, R. W. (1986). Skating on thin ice: Literal meaning and understanding idioms in conversation. Discourse Processes, 9, 17-30.

GIBBS, R. W. (1987). Linguistic factors in children's understanding of idioms. Journal of Child Language, 14, 569-586.

Gibis, R. W., \& Gonzales, G. P. (1985). Syntactic frozenness in processing and remembering idioms. Cognition, 20, 243-259.

Gibbs, R. W., \& NaYaK, N. P. (1989). Psycholinguistic studies on the syntactic behavior of idioms. Cognitive Psychology, 21, 100-138.

Gibes, R. W., Nayak, N. P., Bolton, J. L., \& Keppel, M. E. (1989). Speakers' assumptions about the lexical flexibility of idioms. Memory \& Cognition, 17, 58-68.

Gibbs, R. W., NaYaK, N. P., \& Cutring, J. C. (1989). How to kick the bucket and not decompose: Analyzability and idiom processing. Journal of Memory \& Language, 28, 576-593.

HARLEY, T. (1984). A critique of top-down independent levels models of speech production: Evidence from non-plan-internal speech errors. Cognitive Science, 8, 191-219.

KATZ, J. J. (1973). Compositionality, idiomaticity, and lexical substitution. In S. R. Anderson \& P. Kiparsky (Eds.), A festschrift for Morris Halle (pp. 357-376). New York: Holt, Rinehart \& Winston.

KaTZ, J. J., \& PostaL, P. (1963). Semantic interpretation of idioms and sentences containing them (Quarterly Progress Report No. 70, pp. 275 282). Cambridge, MA: MIT Research Laboratory of Electronics.

LapoinTe, S. G., \& Dell, G. S. (1989). A synthesis of some recent work in sentence production. In G. N. Carlson \& M. K. Tanenhaus (Eds.), Linguistic structure in language processing (pp. 107-156). Dordrecht: Kluwer Academic Publishers.

LeVelt, W. J. M. (1983). Monitoring and self-repair in speech. Cognition, 14, 41-104.

Levelt, W. J. M. (1989). Speaking: From intention to articulation. Cambridge, MA: MIT Press.

LOMBARDI, L., \& PoTTER, M. C. (1992). The regeneration of syntax in short term memory. Journal of Memory \& Language, 31, 713-733.

MACKAY, D. G. (1972). The structure of words and syllables: Evidence from errors in speech. Cognitive Psychology, 3, 210-227. 
MAKKAI, A. (1987), A dictionary of American idioms. New York: Barron's.

McGlone, M. S., Glucksberg, S., \& Cacciari, C. (1994). Semantic productivity and idiom comprehension. Discourse Processes, 17 , 167-190.

Motrey, M. T. (1985, September). Slips of the tongue. Scientific American, 253, 116-127.

Motley, M. T., BaARS, B. J., \& CAmden, C. (1983a). Experimental verbal slip studies: A review and editing model of language encoding. Communication Monographs, 50, 79-101.

Motley, M. T., BaArs, B. J., \& Camden, C. (1983b). Formulation hypotheses revisited: A reply to Stemberger. Journal of Psycholinguistic Research, 12, 561-566.

NuNBERG, G. (1978). The pragmatics of reference. Bloomington: Indiana University Linguistics Club.

RoElofs, A. (1992). A spreading activation theory of lemma retrieval in speaking. Cognition, 42, 107-142.

SHATTUCK-HuFNAGEL, S. (1979). Speech errors as evidence for a serial ordering mechanism in sentence production. In W. E. Cooper \& E. Walker (Eds.), Sentence processing: Psycholinguistic studies presented to Merrill Garrett (pp. 295-324). Hillsdale, NJ: Erlbaum.

Stemberger, J. P. (1982). Syntactic errors in speech. Journal of Psycholinguistic Research, 11, 313-333.

STEMBERGER, J. P. (1985). An interactive activation model of language production. In A. Ellis (Ed.), Progress in the psychology of language (Vol. 1, pp. 143-186). London: Erlbaum.

SwinNey, D. A., \& CuTler, A. (1979). The access and processing of idiomatic expressions. Journal of Verbal Learning \& Verbal Behavior, 18, 523-534.

VAN DER LINDEN, E. (1989). Idioms and flexible categorical grammar. In M. Everaert \& E. Van der Linden (Eds.), Proceedings of the first Tilburg workshop on idioms (pp. 127-143). Tilburg: ITK Proceedings.

Wasow, T., SaG, I. A., \& NunBerg, G. (1983). Idioms: An interim report. In S. Hattori \& K. Inone (Eds.), Proceedings of the XIII International Conference of Linguists (pp. 102-115). Tokyo: CIPL.

Weinreich, U. (1969). Problems in the analysis of idioms. In J. Puhvel (Ed.), Substance and structure of language (pp. 23-81). Berkeley: University of California Press.

WooD, M. (1986). A definition of idiom. Bloomington: Indiana University Linguistics Club.

\section{NOTES}

1. In theories of language production, a speech plan is not a conscious, strategic plot of what to say, but a tacit, abstract representation of the linguistic components of an utterance.

2. This was done to separate "pure production" errors from potential reading errors. The assumption was that if speakers were able to report making the error, then they had not made a reading error. Because the pattern in both sets of errors looked very much like the pattern in the full set, and because the numbers of errors were small, the results are reported in terms of the total error set in each of the experiments.

3. Restricting the analysis to the items that differed in literal meaning, there were 46 errors in the same-meaning-same-syntax condition compared to 24 in the different-meaning same-syntax condition.

\section{APPENDIX}

\section{Idiom Pairings from Experiment 1}

Key: standard idiom (same meaning--same syntax; different meaning-same syntax; different meaning-different syntax)

1 shoot the breeze (chew the fat; raise the roof; nip and tuck)

2 hold your tongue (button your lip; flip your lid; neck and neck)

3 eat your words (swallow your pride; miss the mark; go like clockwork)

4 hit the ceiling (blow a fuse; hold your horses; take by storm)

5 in your tracks (on the spot; up the creek; have dibs on)
6 card up your sleeve (ace in the hole; come to the point; stick your nose into)

7 kick the bucket (meet your maker; hit the bullseye; scream bloody murder)

8 kick in the pants (slap in the face; miss by a mile; catch your death of)

9 line your pockets (feather your nest; steal the show; in the cards)

10 rule the roost (wear the pants; strut your stuff; head over heels)

11 upset the applecart (rock the boat; promise the moon; full of yourself)

12 end of your rope (back to the wall; fly off the handle; in your mind's eye)

13 wrap around your finger (lead by the nose; foam at the mouth; thank your lucky stars)

14 tip the scales (turn the tide; press your luck; heart of gold)

15 knock for a loop (throw for a loss; hit between the eyes; move heaven and earth)

16 head for the hills (take to the woods; grind to a halt; make the fur fly)

17 egg on your face (foot in your mouth; get off your tail; keep your nose clean)

18 rocks in your head (bats in the belfry; get on the stick; on pins and needles)

19 on the ropes (over a barrel; in a fog; nurse a grudge)

20 millstone around your neck (monkey on your back; out of your head; start the ball rolling)

21 throw in the towel (give up the ship; shoot off your mouth; off the beaten track)

22 zip your lip (hold your peace; keep your head; for the birds)

23 have a cow (lose your cool; face the music; on the fly)

24 bed of roses (bowl of cherries; cup of tea; on cloud nine)

25 over your head (beyond your depth; on the ball; set down roots)

26 bat an eye (raise an eyebrow; shake a leg; off the cuff)

27 make the grade (cut the mustard; lay an egg; walk on air)

28 go with the flow (bend with the wind; come to your senses; leave no stone unturned)

29 hit the sauce (wet your whistle; lend a hand; feet of clay)

30 pain in the neck (thorn in the side; feet on the ground; push the panic button)

31 see the light (get the picture; draw a blank; let it rip)

32 weigh one's words (watch your mouth; change your tune; in the pink)

33 take the bull by the horns (take the bit in your mouth; take your life into your hands; straw that breaks the camel's back)

34 lay down the law (put down your foot; take for a ride; turn the tables on)

35 tighten your belt (bite the bullet; lick your chops; make it snappy)

36 lay it on (ham it up; give it up; grease your palm)

\section{Idiom Pairings from Experiment 2}

Key: standard idiom (same figurative; same literal; different figurative; different literal)

1 shoot the breeze (chew the fat; fire the wind; raise the roof; eat the food)

2 swallow your pride (eat your words; chew your ego; miss the mark; throw the ball)

3 hold your tongue (button your lip; grab your lip; flip your lid; sign your name) 
4 hit the ceiling (blow a fuse; smack the roof; hold your horses; read the book)

5 kick the bucket (meet your maker; punt the pail; hit the bullseye; answer the phone)

6 kick in the pants (slap in the face; hit in the trousers; miss by a mile; pick up a penny)

7 rule the roost (wear the pants; command the nest; pull your punches; deposit your check)

8 upset the applecart (rock the boat; overturn the fruitstand; promise the moon; dial the number)

9 end of your rope (back to the wall; last of your string; fly off the handle; put on your shoes)

10 wrap around your finger (lead by the nose; twist around your thumb; foam at the mouth; go to the bank)

11 tip the scales (turn the tide; tilt the balance; hit the road; mail the letter)

12 head for the hills (take to the woods; go to the mountains; grind to a halt; turn on the television)

13 egg on your face (foot in your mouth; yolk on your head; get off your tail; go to the party)

14 rocks in your head (bats in the belfry; stones in your skull; get on the stick; get in your car)

15 monkey on your back (millstone around your neck; chimp on your shoulders; needle in the haystack; coats on the hooks)

16 throw in the towel (give up the ship; toss in the rag; shoot off your mouth; live in the house)

17 zip your lip (hold your peace; fasten your mouth; keep your head; pet your dog)

18 have a cow (lose your cool; own a bull; face the music; buy a bike)

19 bed of roses (bowl of cherries; garden of flowers; cup of tea; glass of milk)

20 make the grade (cut the mustard; get the mark; lay an egg; ask the farmer)

21 go with the flow (bend with the wind; travel with the current; come to your senses; clean out the garage)

22 raise an eyebrow (bat an eye; lift your forehead; shake a leg; see an opera)

23 over your head (beyond your depth; above your face; on the ball; in the kitchen)

24 ace in the hole (card up your sleeve; jack in the pit; come to the point; stir in the cheese)

25 lay down the law (put down your foot; set down the rules; take for a ride; slide down the pole)

26 take the bull by the horns (take the bit in your mouth; take the deer by the antlers; take your life into your hands; take the child to the hospital)
27 hit the sauce (wet your whistle; strike the juice; lend a hand; accept the gift)

28 pain in the neck (thorn in the side; ache in the throat; feet on the ground; fly in the airplane)

29 see the light (get the picture; watch the glow; draw a blank; drink the cola)

30 watch your mouth (weigh your words; see your lips; grease your palm; write your paper)

31 on the spot (in your tracks; atop the dot; up the creek; above the door)

32 line your pockets (feather your nest; pad your pouch; steal the show; tie your laces)

\section{Idiom Pairings from Experiment 3}

Key: Idiom 1 (decomposability rating); Idiom 2 (decomposability rating)

\section{Nondecomposable Idiom Pairs}

1 shoot the breeze (2.3); chew the fat (2.8)

2 line your pockets (2.3); feather your nest (1.7)

3 upset the applecart (2.5); rock the boat (2.5)

4 knock for a loop (2.6); throw for a loss (2.1)

5 rocks in your head (2.4); bats in the belfry (2.4)

6 on the ropes (2.3); over a barrel (2.1)

7 bed of roses (2.3); bowl of cherries (2.2)

8 tighten your belt (2.2); bite the bullet (2.6)

9 lay it on (2.2); ham it up (2.1)

10 raise the roof (2.0); flip your lid (2.9)

\section{Decomposable Idiom Pairs}

11 hold your tongue (4.2); button your lip (4.1)

12 end of your rope (3.2); back to the wall (3.2)

13 wrap around your finger (3.2); lead by the nose (3.2)

14 tip the scales (3.4); turn the tide (3.2)

15 throw in the towel (3.1); give up the ship (4.2)

16 zip your lip (4.0); hold your peace (4.0)

17 over your head (3.5); beyond your depth (3.6)

18 go with the flow (3.8); bend with the wind (3.2)

19 pain in the neck (3.9); thorn in the side (3.5)

20 see the light (3.5); get the picture (3.2)

(Manuscript received January 25, 1995; revision accepted for publication September 26, 1995.) 